$22 \%$, respectively, which is explained by the high incidence of cervical stenosis and endometrial atrophy in patients of the older age group [12,13].

Conclusion. The results of study confirmed that the method of choice for the initial assessment of the endometrial thickness in women with the presence of PB is TVU as a noninvasive and affordable diagnostic method. The diagnostic value of TVU in determining the degree of invasion of myometrium and preoperative staging of endometrial cancer is high. In case of unsatisfactory results of TVU, further instrumental diagnostic research methods are recommended.

$$
* * *
$$

1. Bradley L.D. Investigation of abnormal uterine bleeding in postmenopausal women // Hysteroscopy, 2009.

2. Bugaytsev, S.S., Tyueva, N.V., Shcherbina, A.B. On precancerous pathology, preinvasive and early endometrial cancer // Oncology, 2009, v.11, N 4, p.254

3. Breijer M.C., Timmermans A., van Doorn H.C. Diagnostic strategies for postmenopausal bleeding // Am.J.Obs.Gyn.Int., 2010, p. 850812. DOI:IO.1155/2010/050812.

4. Goldstein S.R. The role of transvaginal ultrasound or endometrial biopsy in the evaluation of the menopausal endometrium // Am.J.Obstet.Gynecol., 2010, vol.202, №3, p.10-11. https://doi.org/10.1016/j.ajog.2009.02.006.

5. Sheshukova N.A., Makarov I.O., Fomina M.N. Endometrial hyperplastic processes: etiopathogenesis, clinic, diagnosis, treatment // Obs.Gyn., 2011, N4, p.16-21.

6. Visser N.C., Breijer M.C., Herman M.C. Factors attributing to the failure of endometrial sampling in women with postmenopausal bleeding // Acta Obstet Gynecol Scand., 2013, vol.92, №10, p.1216-1222. DOI: IO.2147/IJWH.S172696

7. Hartman A, Wolfman W, Nayot D, Hartman M. Endometrial thickness in 1500 asymptomatic postmenopausal women not on hormone replacement therapy // Gynecol. Obstet. Invest., 2013, №75, p.191195. DOI: IO.1159/000347064.

8. Papadia A., Gerbaldo D., Fulcheri E. The risk of premalignant and malignant pathology in endometrial polyps: should every polyp be resected? // Minerva Ginec., 2007, vol.59, №2, p.117-124.

9. Sanam M., Mir Mohammad K.M. Comparison the diagnostic value of dilatation and curettage versus endometrial biopsy by pipelle - a clinical trial Asian Pacific Journal of Cancer Prevention, 2015, vol.16, p.4971-4975. // DOI: http//dx.doi.org/10.7314/APJCP.2015.16.12.4971

10. Sany O., Singh K., Jha S. Correlation between preoperative endometrial sampling and final endometrial cancer histology // Eur J Gynaecol Oncol, 2012, №33, p.142-144.

11. Siam S., Abd El-Hameed A.A. Thickened endometrium in asymptomatic postmenopausal women: Is biopsy mandatory? // Med. J. Cairo. Univ., 2011, №79, p.723-727.

12. Sweet M.G., Schmit Dalton T.A., Weiss P.M. Evaluation and management of abnormal uterine bleeding in premenopausal women // American Family Physician, 2012, №85, p.35-43.

13. van Hanegem N., Prins M.M., Bongers M.Y. The accuracy of endometrial sampling in women with postmenopausal bleeding: a systematic review and meta-analysis // Eur.J.Obstet.Gynecol.Reprod.Biol., 2016, №197, p.147-155. doi:io.1016/j.ejogrb.2015.12.008

\title{
Melikova N.V. \\ Obesity as a risk factor for the development of cardiovascular diseases
}

Azerbaijan Medical University (Azerbaijan, Baku)

doi 10.18411/gq-30-11-2019-08

idsp sciencerussia-30-11-2019-08

\section{Аннотация}

Статья посвящена изучению некоторых биохимических показателей сыворотки крови больных, страдающих от ожирения. Диагностика ожирения, последующий контроль за состоянием больного, оценка эффективности проводимой терапии требуют постоянных заборов крови для анализа. Результаты проведенных исследований еще раз доказали, что у больных, страдающих от ожирения остро нарушается углеводный и липидный обмен и развивается инсулинорезистентность. При ожирении в организме нарушается равновесие про-и антиокидантных систем, повышается активность ферментов антиоксидантных систем SOD, каталазы, GP, в то же время снижается 
активность фермента GSH. При ожирении в организме увеличивается содержание провоспалительных факторов, в особенности интерлейкина-8.

Ключевые слова: ожирение, углеводы, липиды, СОД, каталаза, GP, GSH

Today, obesity is the main risk factor for the development of cardiovascular diseases and complications from them [1,9]. Many epidemiological and clinical studies have shown that obesity, hypertension $(\mathrm{AH})$, increased concentrations of glucose and cholesterol play an important role in the development and mortality of cardiovascular diseases $[1,5]$.

According to the World Health Organization, there are about 2 billion obese patients in the world, and this figure is steadily growing, and therefore obesity is classified as an epidemic of the XXI century[4,6]. On the frequency of obesity in the world the US is leading, $60 \%$ of the population has an overweight, and $30 \%$ corresponds to the criteria for diagnosing obesity. Of particular concern is the fact that obesity is increasingly registered in childhood. Obesity is a serious health risk in general and is accompanied by the development of diseases such as type 2 diabetes, hypertension, coronary heart disease, myocardial infarction, colon and rectal cancer, and in women, in addition - endometrial cancer, cervix, ovaries, mammary glands, which often lead to a fatal outcome $[3,11]$. Absolutely proven is the fact that the risk of mortality from any cause, including cardiovasculardiseases and cancer, increases in men and women of all age groups as the weight increases. Obesity is the main cause of reduced mobility and people's ability to work. This is due to increased load on the musculoskeletal system, damage to the joints of the spine and lower limbs, varicose veins. Obesity leads to a disruption in the function of breathing, because the heavy chest wall limits the amplitude of respiratory movements, and the accumulated fat in the abdominal cavity limits the mobility of the diaphragm, which causes the most frequent complaint of obese - shortness of breath with moderate physical exertion. Often, the cause of death of a obese patient is obstructive sleep apnea syndrome $[13,14]$.

Obesity is a multifactorial chronic disease caused by physical, biochemical, metabolic and behavioral changes that result in increased fat deposition and, correspondingly, weight gain.

The purpose of this study is a comparative study of some biochemical indicators in people suffering from obesity.

Materials and methods of research. Twenty patients with diagnosed obesity aged from 25 to 70 were examined.

To study the components of carbohydrate, lipid metabolism and free radical oxidation, blood plasma was studied in patients. Blood sampling was carried out from the ulnar vein after a twelve-hour fast. Patients with overweight were combined into one group. The study of the parameters of the general blood test was carried out on the apparatus Mythic 18 (Switzerland). The levels of glucose, insulin, C peptide, glycohemoglobin, cholesterol, bChL, aXC, triglycerides, malonicdialdehyde (MDA) and the activity of SOD, catalase, GSH, GP and pro-inflammatory cytokine IL-8 studied.Patients were referred to our laboratory with a diagnosis of metabolic syndrome from various medical institutions. Obesity and two of the four characteristics listed below were considered.

1. Excess body weight, waist circumference in women $>88 \mathrm{~cm}$, in combination with two or more of the following;

2. Arterial hypertension, if the level of SBP> $130 \mathrm{mmHg}$. and or DBP> 85 mmHg.

3. Hypertriglyceridemia, at a triglyceride concentration $>1.7 \mathrm{mmol} / 1$.

4. Low level of high-density lipoprotein cholesterol $<1 \mathrm{mmol} / 1$ for men.

5. Hyperglycemia, if the level of glucose in the blood plasma on an empty stomach> $6.1 \mathrm{mM} / 1$.

The control group consisted of 9 practically healthy persons, comparable in age to the main group. The criterion for inclusion in this group was the absence of chronic diseases in 
the acute stage, acute inflammatory processes and alcohol consumption, not only at the time of the analysis, but also within ten days before the examination. The presence of oxidative stress was determined by the level of products of lipid peroxidation (LPO) and the activity of enzymes of the antioxidant system and interleukin $8[7,8]$.

The statistical analysis of the data was carried out using the SPSS-20 software package.

Results and its discussion. Since obesity is the most important modifiable risk factor for CVD and type 2 diabetes and both conditions have become global in prevalence, a number of researchers have even introduced the term "Diabesity", i.e. "Diapering". The largest diabetic factor of obesity is, perhaps,insulin resistance (IR), determined in persons with excessive body weight long before the manifestation of diabetes mellitus and leading to a violation of b-cell secretion of insulin [10]. Therefore, in patients suffering from obesity in the study of blood plasma, a high level of glucose and insulin was determined. So, in comparison with the control group in patients suffering from general obesity, the glucose concentration statistically significantly increased by $24.8 \%$ and insulin by $22.2 \%$. At that time, the glucochemoglobin concentration was $18.4 \%$ and the C-peptide concentration was $20.5 \%$. All this proves once again that in people with obesity in the blood, the content of glucose, glycohemoglobin, C-peptide and insulin is always higher than normal. Increased parameters of carbohydrate metabolism show that the patient developed insulin resistance.

It is known that insulin is an anabolic hormone, the main function of which is the utilization of glucose and the synthesis of glycogen. However, its role in the regulation of the metabolism goes beyond the regulation of the level of glucose in the blood. Insulin receptors are found in different tissues:

- $\quad$ keletal muscles and myocardium, where glucose utilization takes place;

- adipocytes of adipose tissue, where the inhibition of lipolysis occurs under the influence of insulin;

- smooth muscle cells of blood vessels that undergo GI proliferation;

- vascular endothelium, where insulin affects the synthesis of prostaglandins, nitric oxide, bradykinin (vasodilating effect);

- kidneys, where insulin, acting on the renal tubules, enhances the reabsorption of sodium and water;

- cells of the sympathetic nervous system (SNS) - insulin stimulates the SNS, increasing cardiac output and spasm of peripheral vessels.

Thus, in the conditions of obesity and chronic GI, active lipolysis occurs in the fat stores and an increase in the concentration of free fatty acids (FFA) in the blood, an increase in the thickness of the muscular layer of the vessels and hypertrophy of the myocardium, stimulation of the SNS, increased reabsorption and a decrease in the excretion of sodium and water, properties of insulin due to a deficit in the production of nitric oxide [3]. Therefore, the presence of MI is closely related to the risk of developing CVD associated with atherosclerosis: AH, IHD, stroke, which is proven in numerous studies [2, 12].

In the study of lipid metabolism, it was noted that in patients with obesity in blood plasma, the cholesterol concentration increased by $56.9 \% \mathrm{p}<0.001$, the concentration of triglycerides by $121.4 \%$, the concentration of low-density lipoproteids by $54.9 \% \%$, the concentration of high-density lipoproteins is $18.3 \% \mathrm{p}<0.001$. Our findings once again prove that under the conditions of insulin resistance in obesity, due to a change in the activity of lipoprotein lipase and hepatic triglyceridylase, the disintegration of lipoproteins rich in triglycerides slows down, hypertriglyceridemia develops, which leads to enrichment with triglycerides of HDL and LDL; there is an increase in the concentration of small dense particles of LDL and a decrease in the level of CL HDL plasma. Excess intake of FFA in the liver contributes to the enhancement of the synthesis of triglycerides and the secretion of VLDL and apolipoprotein B. 
In general, with dyslipidemia with obesity, the level of FFA increases, hypertriglyceridemia develops, CL HDL decreases, and CL LDL increases.

The most frequent variant of dyslipidemia in the metabolic syndrome is the lipid triad: a combination of hypertriglyceridemia, a low level of HDL, and an increase in the fraction of fine dense LDL particles [4, 5].Given the role of obesity in the activation of oxidative processes in the body, the content of lipid peroxidation products, in particular malonicdialdehyde, and the activity of enzymes of the antioxidant system in blood plasma were studied. So, when determining the MDA content in blood plasma in patients suffering from obesity, it was noted that the concentration of MDA increased by $286.8 \%$, the activity of the enzyme of the antioxidant system of superoxide dismutase by $44.7 \%$, catalase by $67.2 \%$, while the activity GSH statistically significantly decreased by $34.9 \%$. The concentration of GP also increased by $77.0 \%$.

Hyperproduction of malonic dialdehyde caused by hyperglycemia and an increase in the amount of substrate for oxidation in the form of polyunsaturated fatty acids against the background of a decrease in the activity of the antioxidant defense system causes the development of oxidative stress. The subsequent increase in the products of oxidative modification of proteins and lipids contributes to the pathogenesis of the metabolic syndrome and promotes the development and progression of its complications. The described changes are so interconnected that it is difficult to talk about the primacy of a particular process.

Obviously, in the aggregate of their action, these violations of lipid, carbohydrate metabolism and pro and antioxidant balance significantly increase the course of the metabolic syndrome.

For the first time, we studied the content of interleukin-8 for obesity increased by $115.3 \%$. Obesity is accompanied by a significant increase in the level of IL-8 in plasma, as well as other proinflammatory markers, with the infiltration of macrophages into adipose tissue. For this reason, obesity is considered as a state of chronic subacute inflammation. IL-8 also attracted special attention after it was found a direct relationship between its plasma level and insulin resistance. Nevertheless, data on the association of IL-8,obesity and metabolic syndrome are quite contradictory. Some studies have shown a clear relationship between elevated IL-8 levels with insulin resistance or diabetes 2, while other studies suggest that elevated IL-8 and overweight are not independent risk factors for insulin resistance, since a large mass adipose tissue produces correspondingly more IL-8. Of particular note is the fact that the level of IL-8 is associated not with the body mass index, but with the nature of the distribution of body fat: it has been shown that physical exercises that do not lead to weight loss contribute to a decrease in both the IL-8 level and the amount visceral fat.

\section{Conclusions:}

1. Obesity leads to a violation of carbohydrate and lipid metabolism; as a result, insulin resistance develops.

2. Obesity in the body disturbs the balance of pro-and antioxidant systems, increases the activity of enzymes of antioxidant systems of SOD, catalase, GP and at the same time reduces the activity of the GSH enzyme.

3. When obesity in the body increases the content of proinflammatory factors in particular interleukin-8.

$$
* * *
$$

1. Alexandrov, AA Geometry of the left ventricle, arterial hypertension and obesity: the search for new ways of prevention // Prevention of diseases and health promotion. - 2003. - No. 5. - P. 6-11.

2. Ametov A.S. Insulin secretion and insulin resistance: two sides of the same coin // Problems of endocrinology. 2002. - T.48. - No. 3. - P. 31-37

3. Bugrova S. A. Visceral obesity is the key link in the metabolic syndrome // International Journal of Endocrinology (Ukraine). 2009. - №2 (20). - P. 43-47

4. Metabolic Syndrome / Ed. G.E. Roitberg. M .: MEDpress-inform. -2007.-224 p.

5. Ilyin A.B. Laboratory diagnostics of carbohydrate metabolism disorders. Metabolic syndrome, diabetes mellitus. M. Tver: OOO "Publishing house" Triada ". - 2006. - 128 pp. 
6. Obesity: etiology, pathogenesis, clinical aspects / ed. I.I. Dedova, G.A. Melnichenko. M .: MIA. - 2006. P. 452

7. Radaeva M.V. The state of lipid peroxidation and antioxidant system as a measure of the effectiveness and safety of ozonotherapy / M.V. Radaeva, K.N. Kontorschikova, E.F. The Queen // Kazan Medical Journal. -2007. - № 4. - v. 88,

8. Radaeva M.V. The activity of antioxidant enzymes in normal and oxidative stress is exemplified by the metabolic syndrome. The thesis abstract of Cand. Biol. sciences. N. Novgorod. 2008. - 27 with.

9. Chazova, IE Metabolic syndrome / IE Chazova, VB Mychka. - M.: Media Medica, 2004. - C. 23-24.

10. Blaak E.E. Metabolic fluxes in skeletal muscle in relation to obesity and insulin resistance // Best Pract. Res. Clin. EndocrinolMetab. 2005. - Vol. 19 (3): P. 391403

11. Cahova M, Vavrinkova H, Kazdova L. Glucose-fatty acid interaction in skeletal muscle and adipose tissue in insulin resistance // Physiol. Res. 2007. - Vol. 56. -P. 1-15

12. Meigs J.B., Rutter M.K., Sullivan L.M., Fox C.S., D'Agostino R.B., Wilson P.W.F. Impact of insulin resistance on the face of metabolic syndrome. 2 Diabetes Care. 2007. - Vol. 30. - P. 1219-1225

13. Reaven G. M. The metabolic syndrome: is this diagnosis necessary? // Am. J. Clin.Nutr.-2006-Vol. 83.-P. 1237-1247

14. Sarti C, Gallagher J. The metabolic syndrome: prevalence, CHD risk, and1 treatment // J. Diabetes Complications. 2006. - Vol. 20. - P. 121-132

\section{Moskalets O.V. \\ Potential predictors of outcomes of exudative inflammatory reaction in pseudophakia} Moscow Regional Research Clinical Institute named after M.F.Vladimirskij

(Russia, Moscow)

doi 10.18411/gq-30-11-2019-09

idsp sciencerussia-30-11-2019-09

Introduction. Despite the introduction of minimally invasive surgical technologies, the use of modern biocompatible materials and drugs, the problem of exudative-inflammatory reactions (EVR) of the eye that occur after implantation of intraocular lenses (IOLs) is still relevant. Their frequency ranges from $3.1 \%$ to $13 \%$ [1]. There are infectious EVR caused by different microorganisms, and non-infectious, caused by the reaction of tissues to the surgical trauma itself, IOL or consumables. The timing of the development of EVR ranges from several days to a month or more after surgery. The most severe manifestation is endophthalmitis, which can result in removal of the eye [4]. Predicting the course and outcome of EVR is quite difficult, therefore, the search for laboratory markers that allow this to be done seems quite relevant. Potential candidates include various markers of inflammation and endothelial disfunction, as well as autoantibodies [2,3,5].

The aim of this study was to identify laboratory markers characteristic of various types of EVR in case of pseudophakia.

Material and methods. The study included 21 patients (9 men and 12 women) aged 17 to 69 years with an EVR that developed after phacoemulsification followed by implantation of an IOL. Laboratory studies were performed upon admission to the hospital and before discharge and included bacterial culture from the conjunctival cavities of both eyes, determination of the level of neopterin, antibodies to double-stranded DNA (anti-DNA), soluble adhesion molecules (sICAM-1, sVCAM-1). Subsequently, patients were monitored for 6 months. We used test systems from IBL (Austria), Orgentec (Germany), Bender MedSystems (Austria)

Results. EVR occurred in all patients at different times after surgery (from 2 to 14 days). The severity of EVR distribution was as follows: II degree -8 patients $(38.1 \%)$, III degree -11 patients $(52.3 \%)$, IY degree - 3 patients $(14.3 \%)$.

The initial levels anti-DNA was increased in $12(57.1 \%)$ patients, neopterin in 9 (42.8\%), sICAM-1 in 3 (14.3\%), sVCAM-1 in 5 (23, 8\%). Reliable correlations with the timing of the development of EVR and its severity were not obtained. Large individual fluctuations of indicators were noted. 